\title{
Analysis of Hypoglycemic Episodes in Out Patient Diabetic in Africans Using Ademolus Classification of Hypoglycemia
}

\author{
Adegbenga Bolanle Ademolu \\ Medicine Department, Lagos State University Teaching Hospital, Ikeja, Lagos, Nigeria \\ Email address: \\ ademoluab@yahoo.com \\ To cite this article: \\ Adegbenga Bolanle Ademolu. Analysis of Hypoglycemic Episodes in Out Patient Diabetic in Africans Using Ademolus Classification of \\ Hypoglycemia. International Journal of Diabetes and Endocrinology. Special Issue: Hypoglycemia in Diabetes. \\ Vol. 5. No. 1, 2020, pp. 9-17. doi: 10.11648/j.ijde.20200501.13
}

Received: February 23, 2020; Accepted: March 24, 2020; Published: April 14, 2020

\begin{abstract}
The recent grading of severity of hypoglycemia for use in clinical practice using Ademolus Classification of Hypoglycemia (ACH) is opening a new knowledge path and insight in hypoglycemia complicating diabetes mellitus management. In Africa like other parts of the world, hypoglycemia complicates diabetes mellitus management in in and outpatients. This article aims to examine hypoglycemia occurring in African diabetics on out patient pharmacologic management. This is a retrospective study of 200 hypoglycemic episodes occurring in 88 diabetics attending the out patients of the Endocrinology Clinic of Lagos State University Teaching Hospital, Lagos, Nigeria. Over 13years and 9 months period. Data were analysed using ADEMOLUS CLASSIFICATION OF HYPOGLYCEMIA and American Diabetes Association (ADA)/European Association for the Study of Diabetes (EASD) 2018 Classification of Hypoglycemia. Only documented hypoglycemic episodes were studied using a questionnaire. The inclusion criteria includes known diabetics, documented hypoglycemic episodes occurring during out patient pharmacologic management. This study was analysed using SPSS version 17. Of the 200 hypoglycemic episodes studied, $79.5 \%$ were grade 1 , grade 2 were $18 \%$ while $2.5 \%$ were grade 3 . In all type 2 diabetics (T2DM), $82.9 \%$ had grade 1 hypoglycemia, $14.6 \%$ had grade 2 , while $2.4 \%$ had grade 3 . The lowest hypoglycemic episode among out patient T2DM was an asymptomatic value of $29 \mathrm{mg} / \mathrm{dl}$ (grade 3 hypoglycemia!). There is an inverse relationship between hypoglycemic episodes recorded in type 1 and type 2 diabetics as the pearson correlation was -1.000 . This denotes a perfect negative correlation between hypoglycemic episodes developed in type 1 compared to type 2 diabetics in Africans. There is no linear relationship between these two variables. With a p-value of 0.000 , the null hypothesis is discarded in this study as these findings is not due to chance or error of sampling but rather are statistically significant. ADA/EASD 2018 classification of hypoglycemia is not very sensitive in diagnosing severe hypoglycemia in that it recognized only 1 hypoglycemic episodes while ACH recognizes five. The five cases all have blood sugar of less than $40 \mathrm{mg} / \mathrm{dl}$ yet ADA/EASD 2018 classification recognizes only one because it developed a severe event from hypoglycemia needing assistance from a third party. The majority of T2DM had mild hypoglycemic episodes irrespective of whether they are on oral hypoglycemic agents (OHA) alone, or on OHA and insulin or on insulin alone. Among African T1DM, grade 1 hypoglycemia is twice as common as grade 2 hypoglycemia while severe hypoglycemia is not common. Grades 1, 2 and 3 hypoglycemia can all occur in African diabetics on out patients basis but with the majority occurring as grade 1. Asymptomatic grade 3 hypoglycemia can occur in out patient African T2DM. A similar study is advised in other regions of the world.
\end{abstract}

Keywords: Hypoglycemia, Diabetes Mellitus, Africans, Ademolus Classification of Hypoglycemia, Out Patients

\section{Introduction}

An estimated $8.8 \%$ of world adult population between 20 to 79 years have diabetes mellitus in 2017 , [1] this translate to about 425 millions of world population. An estimated 16 millions of these diabetic figures are in the region of Africa.
It is estimated that in 2017 about 726.7 billion U.S. dollars were spent worldwide on health care expenditure due to diabetes mellitus, out of this only 3.3 billion U.S. dollars was spent in Africa on health care expenditure due to diabetes mellitus!

In a review article of twenty six articles where the costs 
presented in the studies under review is converted to 2015 international dollars prices (I\$) [2]. Annual national direct costs of diabetes differed between countries in Africa and ranged from $\mathrm{I} \$ 3.5$ billion to $\mathrm{I} \$ 4.5$ billion per annum. Indirect costs per patient were generally higher than the direct costs per patient of diabetes. Outpatient costs varied by study design, data source, perspective and healthcare cost and categories included in the total costs calculation. The most commonly included healthcare items were drug costs, followed by diagnostic costs, medical supply or disposable costs and consultation costs. In studies that reported both drug costs and total costs, drug costs took a significant portion of the total costs per patient. The highest burden due to the costs associated with diabetes was reported in individuals within the low income group (2).

The recent grading of severity of hypoglycemia for worldwide use in clinical practice using Ademolus Classification of Hypoglycemia (ACH) is opening new knowledge path and insight in hypoglycemia complicating diabetes mellitus management [3-5].

In Africa like other parts of the world, hypoglycemia complicate diabetes mellitus management not only in inpatients but also in out patients [6,7]. This article aims to examine hypoglycemia occurring in diabetics on out patient pharmacologic management. It is a common experience worldwide that the majority of diabetics are managed as out patients while there are specific indications for admission [810]. Since the majority of diabetics in Africa are out patients, and hypoglycemia occurring in out patient basis is well recognised the question is, do out patient diabetics develop hypoglycemia at the same level of severity or grade? Does the severity of hypoglycemia developed by type 11 diabetics correlate with that developed by type 1 diabetics? Does severe hypoglycemia occur in out patient diabetic with type 1? Does severe hypoglycemia occur in out patient diabetics with type 11 ? What is the commonest grade occurring in out patients type 11 diabetics?

\section{Methodology}

This is a retrospective study of 200 hypoglycemic episodes occurring in out- patient diabetics attending the endocrinology clinic of Lagos State University Teaching Hospital, ikeja, Lagos, Nigeria, between February 2004 to November 2017 a period of 13years and 9 months.
Hypoglycemia was defined as a blood sugar level of $70 \mathrm{mg} / \mathrm{dl}$ or below. Only documented hypoglycemic episodes were used in this study whether symptomatic or asymptomatic. The medical information were retrieved with the aid of a questionaire from the case files (hard copy).

In all 750 (seven hundred and fifty) case files of out patient diabetic were researched, of these 88 diabetics were found to have documented hypoglycemic episodes as out patient. The questionnaire was used to extract relevant information from these 88 African diabetics. It contains two sections A and B. Ademolus Classification of Hypoglycemia was used to define and grade hypoglycemia [3-5]. Similarly, the American Diabetes Association/European Association for the Study of Diabetes 2018 Classification of Hypoglycemia was used to analyse the data.

The inclusion criteria includes known diabetics with documented hypoglycemic episodes occurring during out patient management, diabetics on out patient management on glucose lowering agent whether oral or injectable. The exclusion criteria include all hypoglycemic episodes occurring during inpatient management, probable hypoglycemia in out patient diabetics, hypoglycemia in out patient in non diabetics.

The analysis was done with the aid of SPSS version 17.0

\section{Statistical Analysis}

By using descriptive statistics on the 88 diabetic subjects with 200 hypoglycemic episodes studied, the mean age was 64.7400 years, with a standard error of mean age of 0.80570 . The median age was 63 years, mode was 62 years with a standard deviation of 11.39 years. The range of age was 71 years. In all the diabetics studied both type 1 and type 2 using Ademolus Classification of Hypoglycemia, the frequency of grade 1 was 159 representing $79.5 \%$, the frequency of grade 2 was 36 representing $18 \%$ while the frequency of grade 3 was 5 representing $2.5 \%$. The frequency of hypoglycemia in diabetics both type 1 and 2 on insulin alone or in combination with oral hypoglycemic agents was 59 representing $29.6 \%$ of all hypoglycemic episodes. The frequency of hypoglycemic episodes in type 2 diabetics on oral hypoglycemic agents with or without insulin was 148 episodes representing $74 \%$ of all hypoglycemic episodes occurring in the study (see tables 1-8).

Table 1. Descriptive statistics of hypoglycemic episodes.

\begin{tabular}{|c|c|c|c|c|c|}
\hline & & AGE & GENDER & HYPOGLYCEMIA_VALUE & GRADE_OF_HYPOGLYCEMIA \\
\hline \multirow{2}{*}{$\mathbf{N}$} & Valid & 200 & 200 & 200 & 200 \\
\hline & Missing & $\mathbf{0}$ & $\mathbf{0}$ & $\mathbf{0}$ & $\mathbf{0}$ \\
\hline Mean & & 64.7400 & 1.7700 & 60.2850 & 1.2300 \\
\hline Std. Error of Mean & & .80570 & .02983 & .58052 & .03378 \\
\hline Median & & 63.0000 & 2.0000 & 62.0000 & 1.0000 \\
\hline Mode & & 62.00 & 2.00 & 70.00 & 1.00 \\
\hline Std. Deviation & & 11.39437 & .42189 & 8.20980 & .47775 \\
\hline Variance & & 129.832 & .178 & 67.401 & .228 \\
\hline Range & & 71.00 & 1.00 & 41.00 & 2.00 \\
\hline Minimum & & 16.00 & 1.00 & 29.00 & 1.00 \\
\hline Maximum & & 87.00 & 2.00 & 70.00 & 3.00 \\
\hline
\end{tabular}


Table 1. Continued.

\begin{tabular}{|c|c|c|c|c|c|}
\hline & & TYPE_1_DIABETES & TYPE_2_DIABETES & INSULIN & OHA \\
\hline \multirow{2}{*}{$\mathbf{N}$} & Valid & 200 & 200 & 200 & 200 \\
\hline & Missing & $\mathbf{0}$ & $\mathbf{0}$ & 0 & 0 \\
\hline Mean & & 1.1800 & 1.8200 & 1.2950 & 1.7400 \\
\hline Std. Error of Mean & & .02723 & .02723 & .03233 & .03109 \\
\hline Median & & 1.0000 & 2.0000 & 1.0000 & 2.0000 \\
\hline Mode & & 1.00 & 2.00 & 1.00 & 2.00 \\
\hline Std. Deviation & & .38515 & .38515 & .45719 & .43973 \\
\hline Variance & & .148 & .148 & .209 & .193 \\
\hline Range & & 1.00 & 1.00 & 1.00 & 1.00 \\
\hline Minimum & & 1.00 & 1.00 & 1.00 & 1.00 \\
\hline Maximum & & 2.00 & 2.00 & 2.00 & 2.00 \\
\hline
\end{tabular}

Table 2. Gender distribution of type 1 and type 2 diabetics.

\begin{tabular}{llllll}
\hline & & Frequency & Percent & Valid Percent & Cumulative Percent \\
\hline \multirow{3}{*}{ Valid } & MALE & 46 & 23.0 & 23.0 & 23.0 \\
& FEMALE & 154 & 77.0 & 77.0 & 100.0 \\
& Total & 200 & 100.0 & 100.0 & \\
\hline
\end{tabular}

Table 3. Distribution of raw hypoglycemic values in type 1 and type 2 diabetics.

\begin{tabular}{|c|c|c|c|c|c|}
\hline & & Frequency & Percent & Valid Percent & Cumulative Percent \\
\hline \multirow{33}{*}{ Valid } & 29.00 & 1 & .5 & .5 & .5 \\
\hline & 32.00 & 1 & .5 & .5 & 1.0 \\
\hline & 36.00 & 2 & 1.0 & 1.0 & 2.0 \\
\hline & 38.00 & 1 & .5 & .5 & 2.5 \\
\hline & 42.00 & 1 & .5 & .5 & 3.0 \\
\hline & 44.00 & 3 & 1.5 & 1.5 & 4.5 \\
\hline & 45.00 & 2 & 1.0 & 1.0 & 5.5 \\
\hline & 46.00 & 1 & .5 & .5 & 6.0 \\
\hline & 47.00 & 4 & 2.0 & 2.0 & 8.0 \\
\hline & 48.00 & 3 & 1.5 & 1.5 & 9.5 \\
\hline & 49.00 & 2 & 1.0 & 1.0 & 10.5 \\
\hline & 50.00 & 6 & 3.0 & 3.0 & 13.5 \\
\hline & 51.00 & 6 & 3.0 & 3.0 & 16.5 \\
\hline & 52.00 & 2 & 1.0 & 1.0 & 17.5 \\
\hline & 53.00 & 3 & 1.5 & 1.5 & 19.0 \\
\hline & 54.00 & 3 & 1.5 & 1.5 & 20.5 \\
\hline & 55.00 & 7 & 3.5 & 3.5 & 24.0 \\
\hline & 56.00 & 7 & 3.5 & 3.5 & 27.5 \\
\hline & 57.00 & 5 & 2.5 & 2.5 & 30.0 \\
\hline & 58.00 & 9 & 4.5 & 4.5 & 34.5 \\
\hline & 59.00 & 11 & 5.5 & 5.5 & 40.0 \\
\hline & 60.00 & 4 & 2.0 & 2.0 & 42.0 \\
\hline & 61.00 & 11 & 5.5 & 5.5 & 47.5 \\
\hline & 62.00 & 11 & 5.5 & 5.5 & 53.0 \\
\hline & 63.00 & 16 & 8.0 & 8.0 & 61.0 \\
\hline & 64.00 & 6 & 3.0 & 3.0 & 64.0 \\
\hline & 65.00 & 6 & 3.0 & 3.0 & 67.0 \\
\hline & 66.00 & 8 & 4.0 & 4.0 & 71.0 \\
\hline & 67.00 & 17 & 8.5 & 8.5 & 79.5 \\
\hline & 68.00 & 8 & 4.0 & 4.0 & 83.5 \\
\hline & 69.00 & 14 & 7.0 & 7.0 & 90.5 \\
\hline & 70.00 & 19 & 9.5 & 9.5 & 100.0 \\
\hline & Total & 200 & 100.0 & 100.0 & \\
\hline
\end{tabular}

Table 4. Grades of Hypoglycemia using Ademolus Classification of Hypoglycemia.

\begin{tabular}{llllll}
\hline & & Frequency & Percent & Valid Percent & Cumulative Percent \\
\hline \multirow{4}{*}{ Valid } & 1.00 & 159 & 79.5 & 79.5 & 79.5 \\
& 2.00 & 36 & 18.0 & 18.0 & 97.5 \\
& 3.00 & 5 & 2.5 & 2.5 & 100.0 \\
\hline
\end{tabular}


Table 5. Distribution of Hypoglycemia in Type 1 Diabetes Mellitus.

\begin{tabular}{llllll}
\hline & & Frequency & Percent & Valid Percent & Cumulative Percent \\
\hline \multirow{3}{*}{ Valid } & NO & 164 & 82.0 & 82.0 & 82.0 \\
& YES & 36 & 18.0 & 18.0 & 100.0 \\
& Total & 200 & 100.0 & 100.0 & \\
\hline
\end{tabular}

Table 6. Distribution of hypoglycemia in Type 2 Diabetes Mellitus.

\begin{tabular}{llllll}
\hline & & Frequency & Percent & Valid Percent & Cumulative Percent \\
\hline \multirow{3}{*}{ Valid } & NO & 36 & 18.0 & 18.0 & 18.0 \\
& YES & 164 & 82.0 & 82.0 & 100.0 \\
& Total & 200 & 100.0 & 100.0 & \\
\hline
\end{tabular}

Table 7. Distribution of type 1 and type 2 diabetics on insulin with or without oral hypoglycaemic agent..

\begin{tabular}{llllll}
\hline & & Frequency & Percent & Valid Percent & Cumulative Percent \\
\hline \multirow{3}{*}{ Valid } & NO & 141 & 70.5 & 70.5 & 70.5 \\
& YES & 59 & 29.5 & 29.5 & 100.0 \\
& Total & 200 & 100.0 & 100.0 & \\
\hline
\end{tabular}

Table 8. Distribution of type 2 diabetics on Oral Hypoglycemic Agents with or without insuline.

\begin{tabular}{llllll}
\hline & & Frequency & Percent & Valid Percent & Cumulative Percent \\
\hline \multirow{3}{*}{ Valid } & NO & 52 & 26.0 & 26.0 & 26.0 \\
& YES & 148 & 74.0 & 74.0 & 100.0 \\
& Total & 200 & 100.0 & 100.0 & \\
\hline
\end{tabular}

By using the pearson correlation, there is an inverse relationship between hypoglycemic episodes recorded in type 1 and type 2 diabetics as the Pearson correlation was -1.000 . This denotes a perfect negative correlation between hypoglycemic episodes developed in type 1 compared to type
2 diabetics. There is no linear relationship between these two variables. With a p-value of 0.000 , the null hypothesis is discarded in this study as the findings of this study are not due to chance or error of sampling but rather are statistically significant (see tables 9).

Table 9. Correlation of hypoglycemic episodes between type 1 and type 2 diabetics.

\begin{tabular}{llll}
\hline & & TYPE_1_DIABETES & TYPE_2_DIABETES \\
\hline \multirow{2}{*}{ TYPE_1_DIABETES } & Pearson Correlation & 1 & $-1.000^{* *}$ \\
& Sig. (2-tailed) & & .000 \\
& $\mathrm{~N}$ & 200 & 200 \\
TYPE_2_DIABETES & Pearson Correlation & $-1.000^{* *}$ & 1 \\
& Sig. (2-tailed) & .000 & 200 \\
\hline
\end{tabular}

**. Correlation is significant at the 0.01 level (2-tailed).

\section{Results}

\subsection{Analysis Using Ademolus Classification of Hypoglycemia}

The 88 diabetics studied had a total of 200 hypoglycemic episodes as out patients. This approximate to two hypoglycemic episodes per diabetic. Of the 88 diabetics, 4 (4.5\%) had previous history of hospitalization but only hypoglycemic episodes occurring during their out patient management were involved in this study.

The age range among the 88 African diabetics was 16 to 87 years. The mean age was 64.74 years. The median age was 63years. The male to female ratio was 2:7.

The total hypoglycemic episodes studied on out patient basis was 200 episodes. 166 episodes (83\%) occurred in 84 subjects with Type 2 diabetics while 34 episodes (17\%) occurred in 4 subjects with type 1 . Hence roughly there were 2 episodes of hypoglycemic episodes per type 2 diabetics whereas there are in average 8.5 hypoglycemic episodes per type 1 diabetics.

The range of values of out patient hypoglycemic episodes was from 29 to $70 \mathrm{mg} / \mathrm{dl}$.

The mean of the raw value of hypoglycemic episodes was $60.28 \mathrm{mg} / \mathrm{dl}$ (grade 1).

The mode was $70 \mathrm{mg} / \mathrm{dl}$ (grade 1) with a total of 19 separate hypoglycemic episodes. The median was $62 \mathrm{mg} / \mathrm{dl}$ (grade 1).

Grade 1 hypoglycemic episodes were 159 in all forming $79.5 \%$.

Grade 2 hypoglycemic episodes were 36 episodes forming $18 \%$ while Grade 3 episodes were 5 episodes forming $2.5 \%$ (see figure 1).

There were no records of grade 4 hypoglycemic episodes 
in this study in the African diabetics studied whether they have type 1 or type 2 diabetes mellitus.

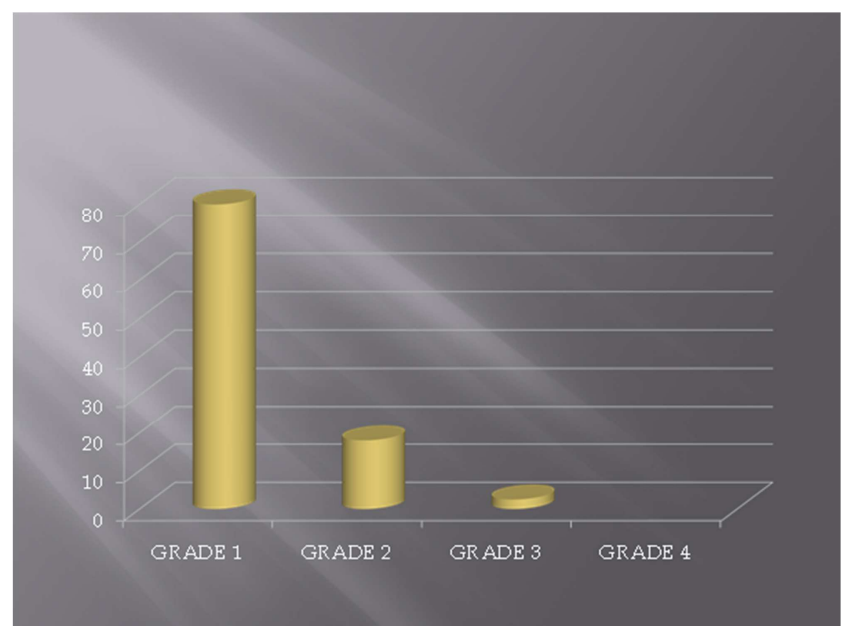

Figure 1. Percentage Distribution of Grades of Hypoglycaemia in OutPatient African Type 1 and 2 Diabetics Using Ademolus Classification of Hypoglycemia $($ Ach) $(N=200)$.

Out of the 166 hypoglycemic episodes in type 2 diabetics, $136(81.93 \%)$ were grade 1 , twenty six (26) representing $15.66 \%$ were grade 2 hypoglycemia, while 4 (2.41\%) were grade 3 (see figure 2).

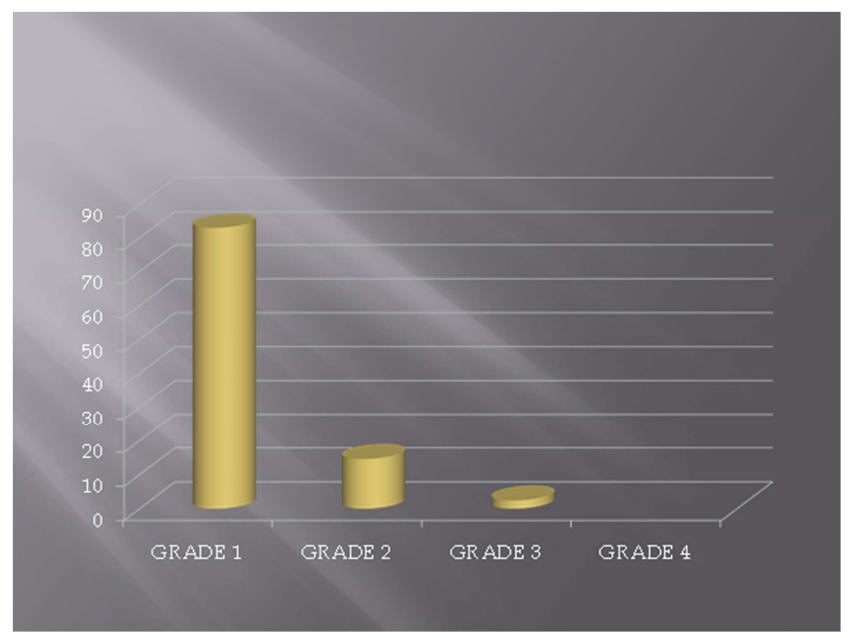

Figure 2. Percentage Distribution of Grades of Hypoglycemia in OutPatients African Type 2 Diabetics Using Ademolus Classification of Hypoglycemia $(\mathrm{ACH})(\mathrm{N}=166)$.

Of the 84 African diabetics with type 2 diabetes 67 (79.7\%) had only grade 1 hypoglycemic episodes during the study period while $17(20.2 \%)$ had either grade 1,2 or 3 at one time or the other.

Type 2 diabetics on oral hypoglycemic agents alone had a total of 141 hypoglycemic episodes. Of these 120 hypoglycemic episodes $(85.11 \%)$ were grade 1, 20 episodes $(14.18 \%)$ were grade 2 , while 1 episode of hypoglycemia $(0.71 \%)$ occurred as grade 3 (see figure 3 ).

Type 2 diabetics on oral hypoglycemic agents and insulin had a total of 7 hypoglycemic episodes all of which were grade 1 (see figure 4 ).

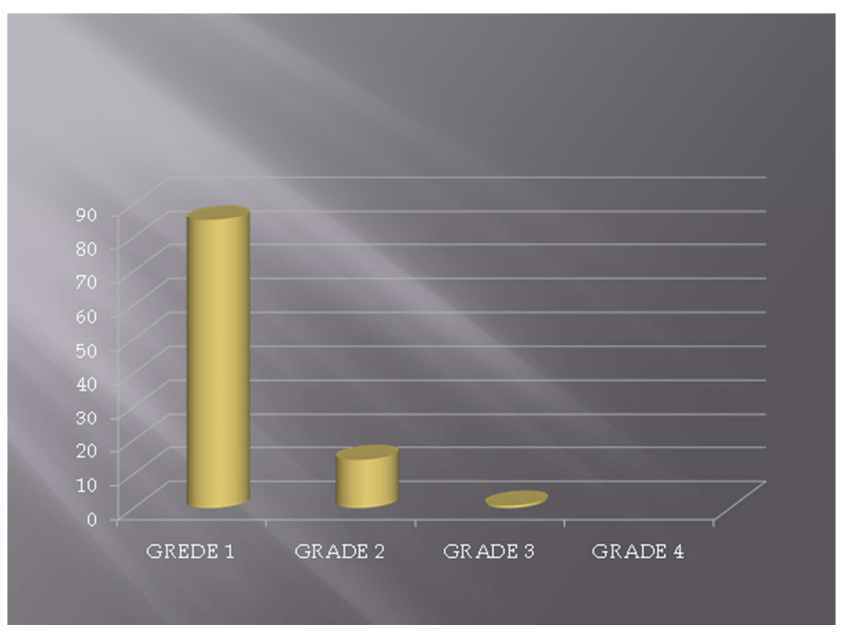

Figure 3. Percentage Distribution of Grades of Hypoglycemia in OutPatient African Type 2 Diabetics on Oral Hypoglycemic Agents Alone Using Ademolus Classification of Hypoglycemia $(A C H)(N=141)$.

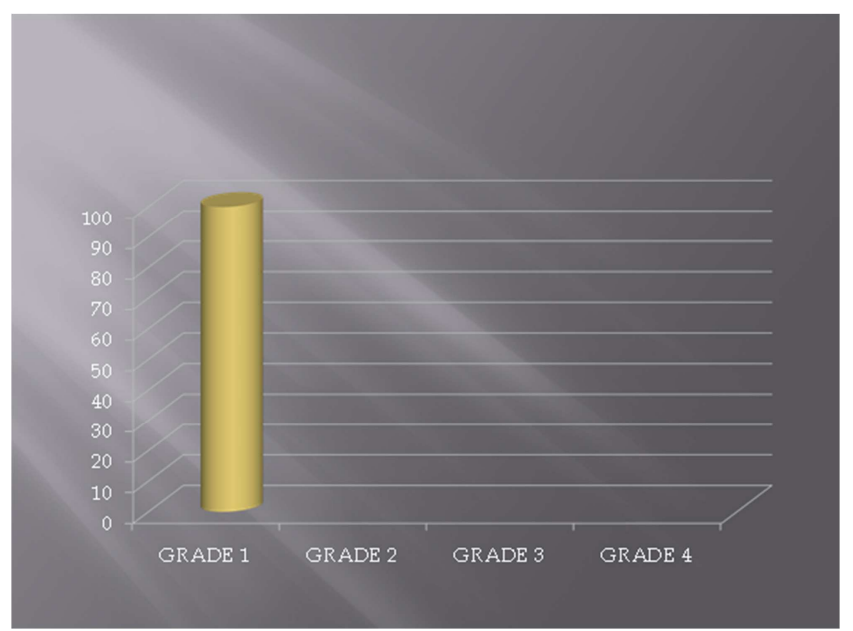

Figure 4. Percentage Distribution of Grades of Hypoglycemia in OutPatient African Type 2 Diabetics on Oral Hypoglycemic Agents and Insulin Using Ademolus Classification of Hypoglycemia $(\mathrm{ACH})(\mathrm{N}=7)$.

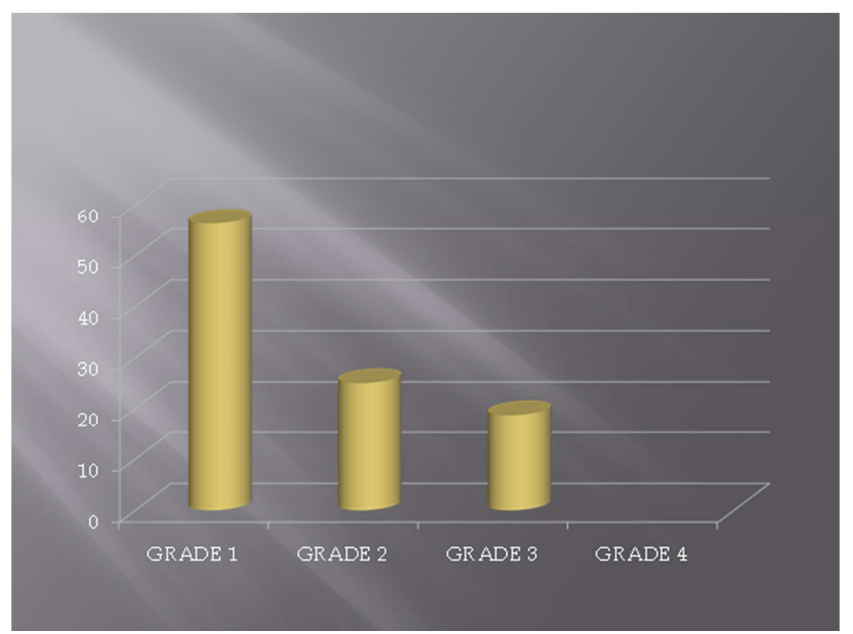

Figure 5. Percentage Distribution of Grades of Hypoglycemia in OutPatient African Type 2 Diabetics on Insulin Alone Using Ademolus Classification of Hypoglycemia $(A C H)(N=16)$.

Type 2 diabetic on insulin alone had a total of 16 
hypoglycemic episodes. Nine (9) representing 56.3\% were grade 1 , four (4) representing $25 \%$ were grade 2 while three (3) representing $18.7 \%$ were grade 3 (see figure 5 ).

Type 1 diabetics with 34 hypoglycemic episodes had 21 episodes (61.75\%) occurring as grade 1 hypoglycemia. twelve (12) representing (35.29\%) occurred as grade 2 while one episode $2.94 \%$ occurred as grade 3 hypoglycemia (see figure 6).

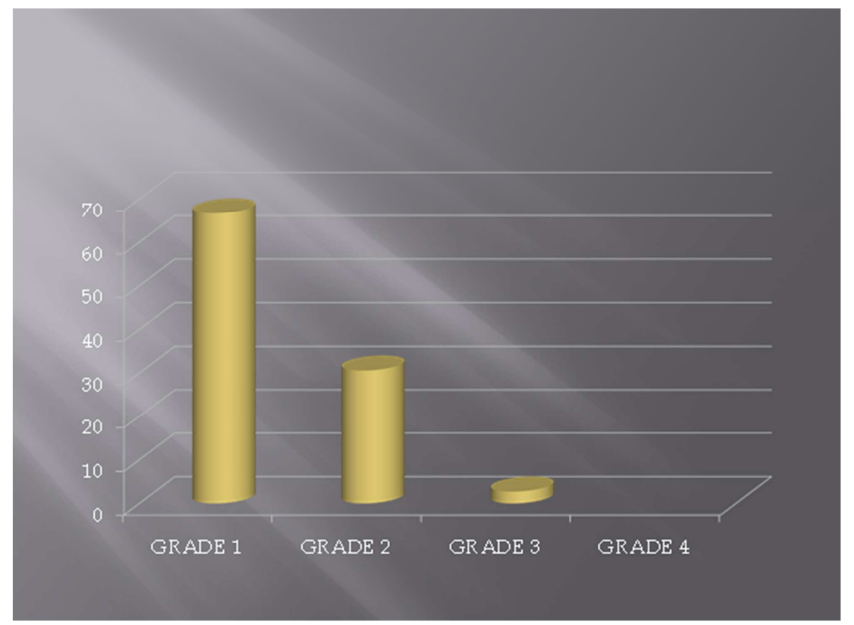

Figure 6. Percentage Distribution of Grades of Hypoglycemia in OutPatient African Type 1 Diabetics on Insulin Using Ademolus Classification of Hypoglycemia $(\mathrm{ACH})(\mathrm{N}=36)$.

The lowest hypoglycemic episode among type 2 subjects studied was an asymptomatic value of $29 \mathrm{mg} / \mathrm{dl}$ which is grade 3 hypoglycemia. The lowest hypoglycemic episode among type 1 diabetics was a value of $38 \mathrm{mg} / \mathrm{dl}$ which is grade 3 hypoglycemia.

\subsection{Analysis Using the 2018 American Diabetes Association/European Association for the Study of Diabetes (ADA/EASD) Classification of Hypoglycemia}

By using the same sample size of 88 diabetic patients, the hypoglycemic episodes were analysed using the 2018 ADA/EASD classifications of hypoglycemia [11].

The total number of hypoglycemic episodes based on this 2018 ADA/EASD classification of hypoglycemia was 181 hypoglycemic episodes. The 2018 ADA/EASD classification defines hypoglycemia as less than $70 \mathrm{mg} / \mathrm{dl}$. This reduced the original 200 hypoglycemic episodes from 200 to 181 since nineteen episodes of hypoglycemia occurred at random blood sugar of $70 \mathrm{mg} / \mathrm{DL}$. This reduction in number is a biochemical reduction which may not necessarily translate to reduction in clinical features or symptoms. It is worth nothing that during the study period (February 2004 to November 2017), ADA recognizes blood sugar level of $70 \mathrm{mg} / \mathrm{dl}$ as hypoglycemia!

The total number of diabetics involved in the study also was reduced by ADA/EASD Classification from 88 diabetics to 85 diabetics. This is because three diabetics only have hypoglycemic episodes at $70 \mathrm{mg} / \mathrm{dl}$ each based on ADEMOLUS CLASSIFICATION OF HYPOGLYCEMIA.
(Again, it is worth nothing that during the study period, ADA recognizes blood sugar level of $70 \mathrm{mg} / \mathrm{dl}$ as hypoglycemia!).

There were 34 episodes of hypoglycemia in type 1 which were 4 diabetics and 147 episodes in type 2 which were 81 diabetic subjects, these brings it to average of 1.7 episodes per type 2 diabetics and 8.5 episodes per type 1 diabetics.

Overall in both type 1 and type 2 diabetics, level 1 hypoglycemia were 141 episodes $(77.9 \%)$, level 2 were 39 episodes $(21.55 \%)$, level 3 hypoglycemia was one episode $(0.55 \%)$ see figure 7 .

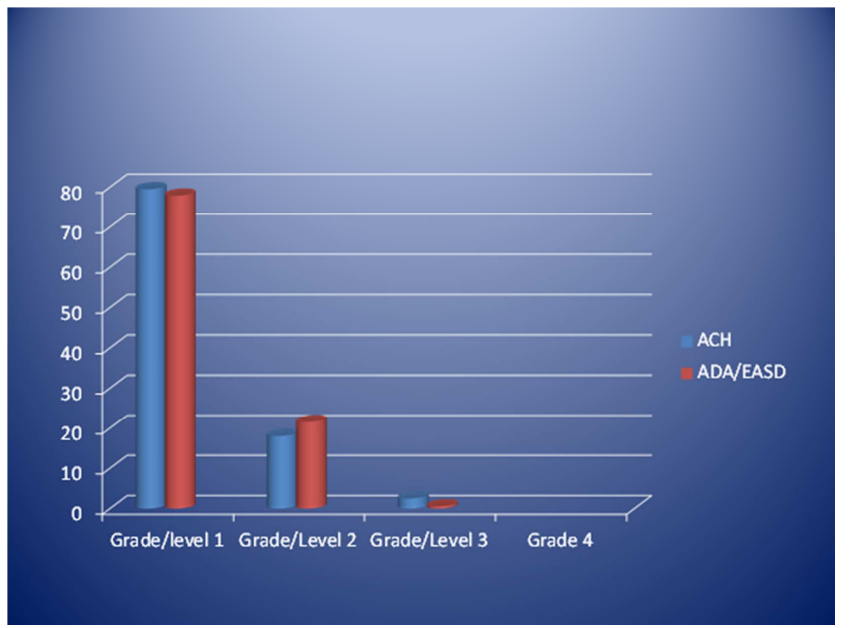

Figure 7. Comparison Between Ademolus Classification of Hypoglycemia $(A C H) \quad(N=200)$ and American Diabetes Association (ADA)/European Association for the Study of Diabetes (EASD) 2018 Classification of Hypoglycemia $(N=181)$ in Percentages in Out-Patient Diabetics in Africa.

In type 2 diabetics, level 1 hypoglycemia were 118 episodes $(80.27 \%)$, level 2 hypoglycemia were 28 episodes $(19.05 \%)$, level 3 hypoglycemia was $1(0.68 \%)$ see figure 8 .

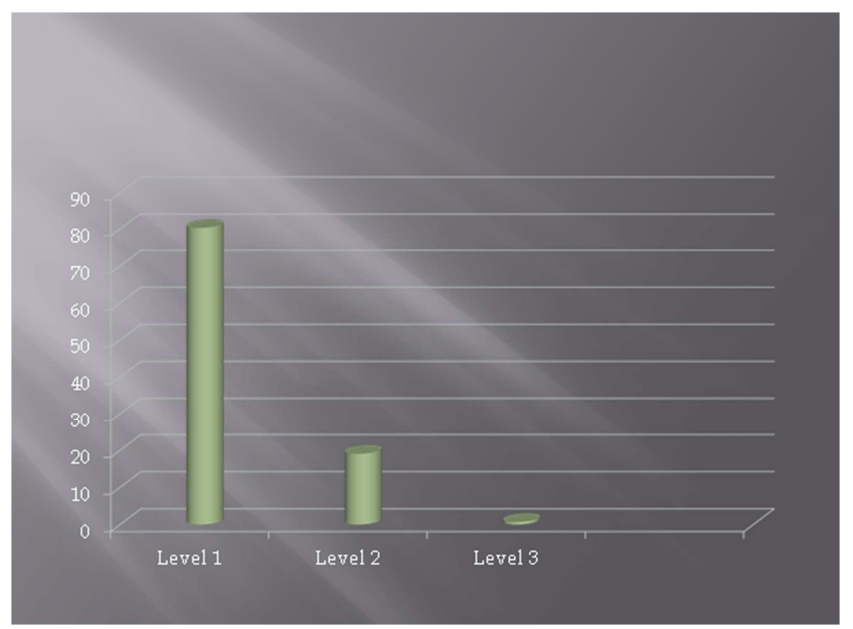

Figure 8. Percentage Distribution of Grades of Hypoglycemia in OutPatients African Type 2 Diabetics Using American Diabetes Association/European Association for the Study of Diabetes 2018 Classification of Hypoglycemia $(N=147)$.

In type 1 diabetics, level 1 hypoglycemia were 23 episodes (67.65\%), level 2 hypoglycemia were 11 episodes (32.35\%). There were no level three hypoglycemia among type 1 diabetics in this study. 


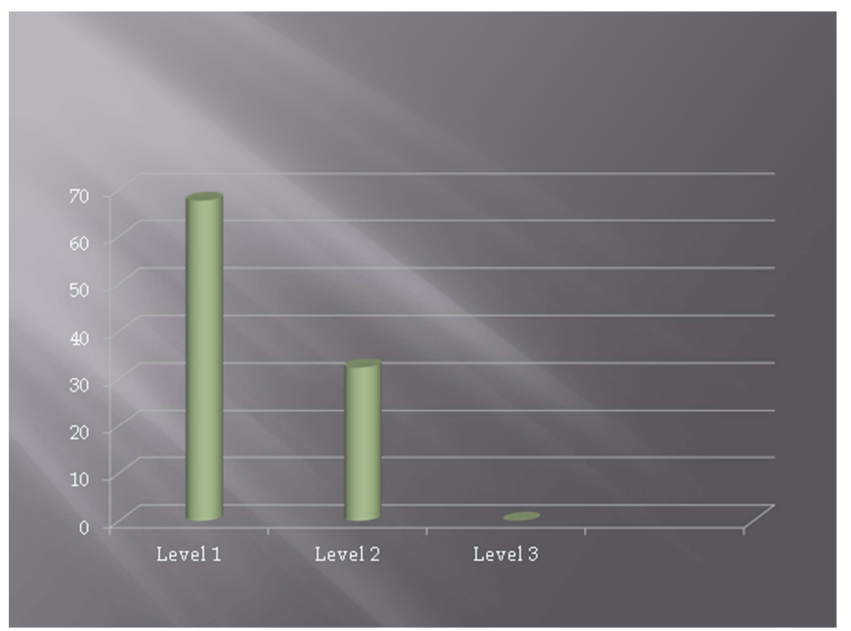

Figure 9. Percentage Distribution of Grades of Hypoglycemia in OutPatients African Type 1 Diabetics Using American Diabetes Association/European Association for the Study of Diabetes 2018 Classification of Hypoglycemia $(N=34)$.

\section{Discussion}

\subsection{Ademolus Classification of Hypoglycemia in Out Patient African Diabetics}

The majority ( $80 \%$ ) of out patient hypoglycemic episodes in Africans diabetics are mild which is grade 1 while only a minute proportion $2.5 \%$ develop severe hypoglycemic episodes as out patient.

Very severe forms of hypoglycemic episodes (grade 4) were not recorded over the 13 years and 9 months period of study in this research.

The type 2 diabetics in this study had mild hypoglycemic episodes mostly, though in varying degree, irrespective of whether they are on oral hypoglycemic agents (OHA) alone, or on OHA and insulin or whether they are on insulin only. Those on OHA and insulin in this study all had mild hypoglycemia, however this is not to say that moderate to severe hypoglycemia cannot occur in this group, the possible explanation for all the subjects having mild hypoglycemic episodes in this study might be due to the very small size of this category and the fact that all the subjects involved were on small doses of insulin combined with their OHA compared to those on insulin alone who had $56.3 \%$ of hypoglycemic episodes as been mild. $25 \%$ as being moderate and $18.7 \%$ as being severe, who were all on high doses of insulin.

The lowest hypoglycemic episode among the type 2 subjects was a value of $29 \mathrm{mg} / \mathrm{dl}$ occurring in an out patient and was asymptomatic! The doctor noticed and pen this down in the case file therefore asymptomatic hypoglycemia can occur in grade 3 in African diabetics on out patient management.

Among type 1 African diabetics in this study, mild (grade 1) hypoglycemia is twice as common as moderate (grade 2) hypoglycemia while severe hypoglycemia is not common in out patients with only $2.7 \%$ occurring in them $[12,13]$.

The lowest value of hypoglycemic episode in type 1 African diabetics in this study was $38 \mathrm{mg} / \mathrm{dl}$ (Grade 3 ). It was symptomatic.

Further analysis of the cases showed the following findings; a 63 years old male type 2 diabetic patients of 37 years duration had series of hypoglycemic episodes. Her fasting blood sugar done in the laboratory on an occasion (not glucometer) was $36 \mathrm{mg} / \mathrm{dl}$ as an out patients, her two hours post prandial was $59 \mathrm{mg} / \mathrm{dl}$. On her clinic day where the result was presented, her fasting blood sugar using glucometer was $32 \mathrm{mg} / \mathrm{dl}$, the doctor recorded in the case note that no symptoms of hypoglycemia were present. The doctor stopped the premix insulin (mixtard) also all oral hypoglycemic agents were stopped. On another day, she had a fasting blood sugar of $36 \mathrm{mg} / \mathrm{dl}$ and a two hours post prandial of $220 \mathrm{mg} / \mathrm{dl}$, the laboratory technologist minuted on the laboratory form that "both test were repeated twice to be sure of the results given".

Some outpatients with hypoglycemia don't present immediately some get resolved a times before presentation [14]. This is seen in a 71 years old male type 2 diabetic who presented two days after he had a asymptomatic hypoglycemia of $67 \mathrm{mg} / \mathrm{dl}$ (grade 1 hypoglycemia) on presentation his random blood sugar was $129 \mathrm{mg} / \mathrm{dl}$. A 63 years old man with type 2 diabetes also had asymptomatic hypoglycemia which was noted in the case note by the doctor at fasting blood sugar of $29 \mathrm{mg} / \mathrm{dl}$. An 81 years old type 2 diabetic had repeated episodes of hypoglycemia in a year as out patient but none warranted admission.

A 60 years old man had hypoglycemia post hospital discharge as an out patient [15]. A 52 years old man with type 2 diabetes had hypoglycemia which had resolved before presenting to the hospital. A 67 years old type 2 diabetic woman had asymptomatic hypoglycemia at $49 \mathrm{mg} / \mathrm{dl}$.

A 33 years old type 1 diabetic man previously admitted and was discharged and had hypoglycemia as out patient [15]. A 60 years old type 2 diabetic woman had a fasting blood sugar of $63 \mathrm{mg} / \mathrm{dl}$ and a two hours post prandial of $64 \mathrm{mg} / \mathrm{dl}$, this shows that nutrition alone may not correct hypoglycemia adequately in some diabetics, though this depend on glycemic index. A 52years old female type 2 diabetic had a fasting blood sugar of $45 \mathrm{mg} / \mathrm{dl}$ she took milo (a beverage) and her blood sugar became $69 \mathrm{mg} / \mathrm{dl}$. An 82 years old type 2 diabetic had several episodes of hypoglycemia as out patients but no admission.

\subsection{Ademolus Classification of Hypoglycemia and ADA/EASD 2018 Classification of Hypoglycemia in Out Patient African Diabetics}

ADA/EASD 2018 classification of hypoglycemia is not very sensitive in diagnosing severe hypoglycemia in that it recognized only one hypoglycemic episodes $(0.55 \%$ of its study population of 181 hypoglycemic episodes) while $\mathrm{ACH}$ recognizes five cases $(2.5 \%$ of its study population of 200 hypoglycemic episodes) see figure 7.

The five cases all had blood sugar of less than $40 \mathrm{mg} / \mathrm{dl}$ yet ADA/EASD 2018 classification recognizes only one because it developed a severe event from hypoglycemia needing assistance from a third party, meanwhile the other four 
hypoglycemic episodes though less than $40 \mathrm{mg} / \mathrm{dl}$ in absolute value biochemically were not seen as being severe despite the fact that they are out patients that may suddenly become symptomatic in the public irrespective of public function they are involved in! Even the lowest hypoglycemic episode of $29 \mathrm{mg} / \mathrm{dl}$ among the five hypoglycemic episodes was not recognised by ADA/EASD 2018 classification of hypoglycemia as level 3 (severe hypoglycemia) because it was asymptomatic!

This is dangerous! A similar limitation of the ADA/EASD 2018 classification of hypoglycemic episodes was found in in patients in previous study [5].

This study validates ADEMOLUS CLASSIFICATION OF HYPOGLYCEMIA just as the previous study [5] also did in in-patients.

Now that ADEMOLUS CLASSIFICATION OF HYPOGLYCEMIA is validated, It should be noted that application of ADEMOLUS CLASSIFICATION OF HYPOGLYCEMIA is not only in diabetics but also in non diabetic including those that may have hypoglycemia complicating any drug therapy like hydroxylchoroquine particularly now that the use of hydroxylchloroquine a therapeutic cause of hypoglycemia is in use as clinical trial for treatment of severe acute respiratory syndrome coronavirus 2 (SARS-CoV-2) infection, that is COVID 19 in the United States and some parts of the world [16].

\section{Conclusion}

There is an inverse relationship between hypoglycemic episodes recorded in type 1 and type 2 diabetics as the Pearson correlation was -1.000 . This denotes a perfect negative correlation between hypoglycemic episodes formed in type 1 compared to type 2 diabetics in Africans.

Mild (grade 1), moderate (grade 2) and severe (grade 3) can all occur in African diabetics on out patients basis but with the majority of the episodes occurring as grade 1 . Asymptomatic grade 3 hypoglycemia can occur in type 2 African diabetics. A similar study is advised in other regions of the world.

\section{Acknowledgements}

I want to thanks my numerous diabetic patients I have ever come across and read about in my career and practice in public and private healthcare sector for giving me the opportunity to learn hypoglycemia as it affects diabetology and other areas of medicine in them and through them. To God be the glory for the successful publishing of this article which I admit was an herculean task made possible by God in whom I trust.

\section{References}

[1] Health care expenditure due to diabetes worldwide in 2017, by region (in billion U.S. dollars).
[2] Chipo Mutyambizi, Milena Pavlova, Lumbwe Chola, Charles Hongoro, and Wim Groo. Cost of diabetes mellitus in Africa: a systematic review of existing literature. Global Health. 2018; 14: 3 .

[3] Ademolu AB, Ademolu AO, Ogbera AO, Fasanmade OA. (2015) Hypoglycemia in lkorodu. Journal of Asian Health.

[4] Ademolu AB (2017) Role of Ademolus Classification of Hypoglycemia in Blood Glucose and Diabetes Mellitus Management. Gastroenterol Liver Clin Med (2017) 1: 1003.

[5] Adegbenga B Ademolu (2019) Analysis of Hypoglycemic Episodes in Diabetics in Africans Using Ademolus Classification of Hypoglycemia (ACH). Acta Scientific Medical Sciences 3 (3): 138-145.

[6] Halefom Kahsay, Bereket Fantahun, Teshome Nedi, and Gebre Teklemariam Demoz. Evaluation of Hypoglycemia and Associated Factors among Patients with Type 1 Diabetes on Follow-Up Care at St. Paul's Hospital Millennium Medical College, Addis Ababa, Ethiopia Journal of Diabetes Research. Volume 2019. Article ID 9037374.

[7] Andrew J Karter, Kasia J Lipska, and John F. Steiner. High Rates of Severe Hypoglycemia among African American Patients with Diabetes: The Surveillance, Prevention, and Management of Diabetes Mellitus (SUPREME-DM) Network. J Diabetes Complications. 2017 May; 31 (5): 869-873.

[8] American Diabetes Association. Hospital Admission Guidelines for Diabetes. Diabetes Care 2004 Jan; 27 (suppl 1): s103-s103.

[9] Myriam Zaydee Allende-Vigo, Rafael A. González-Rosario, and Raul O. Ramón, Inpatient Management of Diabetes Mellitus Among Noncritically Ill Patients At The University Hospital Of Puerto Rico. Endocr Pract. 2014 May; 20 (5): 452-460.

[10] Ojobi JE, Dunga J, Ogiator MO, Mbaave P, Bello RN. INDICATIONS AND OUTCOME OFADMISSION OF DIABETIC PATIENTS INTO THE MEDICALWARDS IN A NIGERIAN TERTIARY HOSPITAL- ATWO YEAR REVIEW. Jos Journal of Medicine, Volume 11 No. 2.

[11] American Diabetes Association. "Standards of Medical Care in Diabetes-2019”. Diabetes Care 42 (2019): S1-S2.

[12] Alessandro Mantovani, Giorgio Grani, [...], and Enzo Bonora. Severe hypoglycemia in patients with known diabetes requiring emergency department care: A report from an Italian multicenter study. J Clin Transl Endocrinol. 2016 Sep; 5: 4652 .

[13] Yon Su Kim, Be Long Cho, and Chang Gyu Park. Frequency and Severity of Hypoglycemia in Type 2 Diabetes Mellitus Patients Treated with a Sulfonylurea-Based Regimen at University-Affiliated Hospitals in Korea: The Naturalistic Evaluation of Hypoglycemic Events in Diabetic Subjects Study. Korean J Fam Med. 2019 Jul; 40 (4): 212-219.

[14] Philip E. Cryer, Stephen N. Davis, and Harry Shamoon, M. Hypoglycemia in Diabetes. Diabetes Care 2003 Jun; 26 (6): 1902-1912.

[15] Adriana M. Hung,; Edward D. Siew; Otis D. Wilson; Amy M. Perkins; Robert A. Greevy; Jeffrey Horner et al. Risk of Hypoglycemia Following Hospital Discharge in Patients With Diabetes and Acute Kidney Injury Diabetes Care 2018 Mar; 41 (3): 503-512. 
[16] Gautret P, Lagier JC, Parola P, Hoang VT, Meddeb L, Mailhe $\mathrm{M}$ et al. Hydroxychloroquine and azithromycin as a treatment of COVID-19: results of an open-label non-randomized clinical trial. Int J Antimicrob Agents. 2020 Mar 20: 105949. 